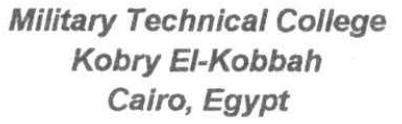

$10^{\text {th }}$ International Conference

On Aerospace Sciences\&

Aviation Technology

\title{
An Investigation into the Performance of a Homing Guided Missile with Different Aerodynamic Configurations
}

\author{
G. A. El-Sheikh
}

\begin{abstract}
The response of a guided missile as a whole depends upon the control system characteristics and the missile aerodynamic configuration. Thus, this paper tries to investigate the performance of a homing guided missile utilizing the proportional navigation guidance method with different missile aerodynamic configurations. These configurations include the variable incidence wing, the canard control, and the tail control configurations. The results obtained showed that the missile with only rate feedback and variable incidence wing configuration responds quicker than other configurations. In addition, the oscillation frequency of the response is very close to that of the missile alone. While using the rate and acceleration feedbacks together yields that the missile with tail control configuration responds faster than other configurations. In addition, the oscillation frequency of the response is higher than that of the missile alone, but with different navigation ratio corresponding to each configuration.
\end{abstract}

\section{Keywords:}

Missile Guidance Systems, Guidance Methods, Automatic Control, and Flight Mechanics

\section{Nomenclature:}

$\begin{array}{ll}\mathrm{V}_{\mathrm{M}} & {[\mathrm{m} / \mathrm{sec}]} \\ \mathrm{V}_{\mathrm{T}} & {[\mathrm{m} / \mathrm{sec}]} \\ \mathrm{V}_{\mathrm{C}} & {[\mathrm{m} / \mathrm{sec}]} \\ \mathrm{m} & {[\mathrm{kg}]} \\ \mathrm{I}_{\mathrm{y}} & {\left[\mathrm{kg}-\mathrm{m}^{2}\right]} \\ \mathrm{i}_{\mathrm{y}} & {\left[\mathrm{sec}^{2}\right]} \\ \mathrm{S}_{\mathrm{b}} & {\left[\mathrm{m}^{2}\right]} \\ \mathrm{S}_{\mathrm{f}} & {\left[\mathrm{m}^{2}\right]} \\ \mathrm{S}_{\mathrm{r}} & {\left[\mathrm{m}^{2}\right]} \\ \mathrm{q} & \\ \ell_{\mathrm{f}}, \ell_{\mathrm{r}} & {[\mathrm{m}]} \\ \ell & {[\mathrm{m}]} \\ \ell & {[\mathrm{m}]} \\ \tau & {[\mathrm{sec}]}\end{array}$

\author{
Missile flight speed \\ Target flight speed \\ Relative missile-target flight (closing) speed \\ Missile mass \\ Moment of inertia in pitch \\ $=I_{y} /\left(q S_{b} D\right)$ \\ Maximum missile body cross-sectional area \\ Exposed area of two front surface panels \\ Exposed area of two rear surface panels \\ The dynamic pressure and is given by: $\rho V_{M}^{2} / 2$ \\ Distance between the center-of-gravity and the center-of-pressure of \\ front and rear control surfaces, respectively. \\ Distance between the center-of-pressure due to the angle of attack and \\ the center-of-pressure due to the deflection of control surfaces. \\ Missile body diameter \\ Time constant given by: $2 \mathrm{~m} /\left(\rho \mathrm{V}_{\mathrm{M}} \mathrm{S}_{\mathrm{b}}\right)$
}




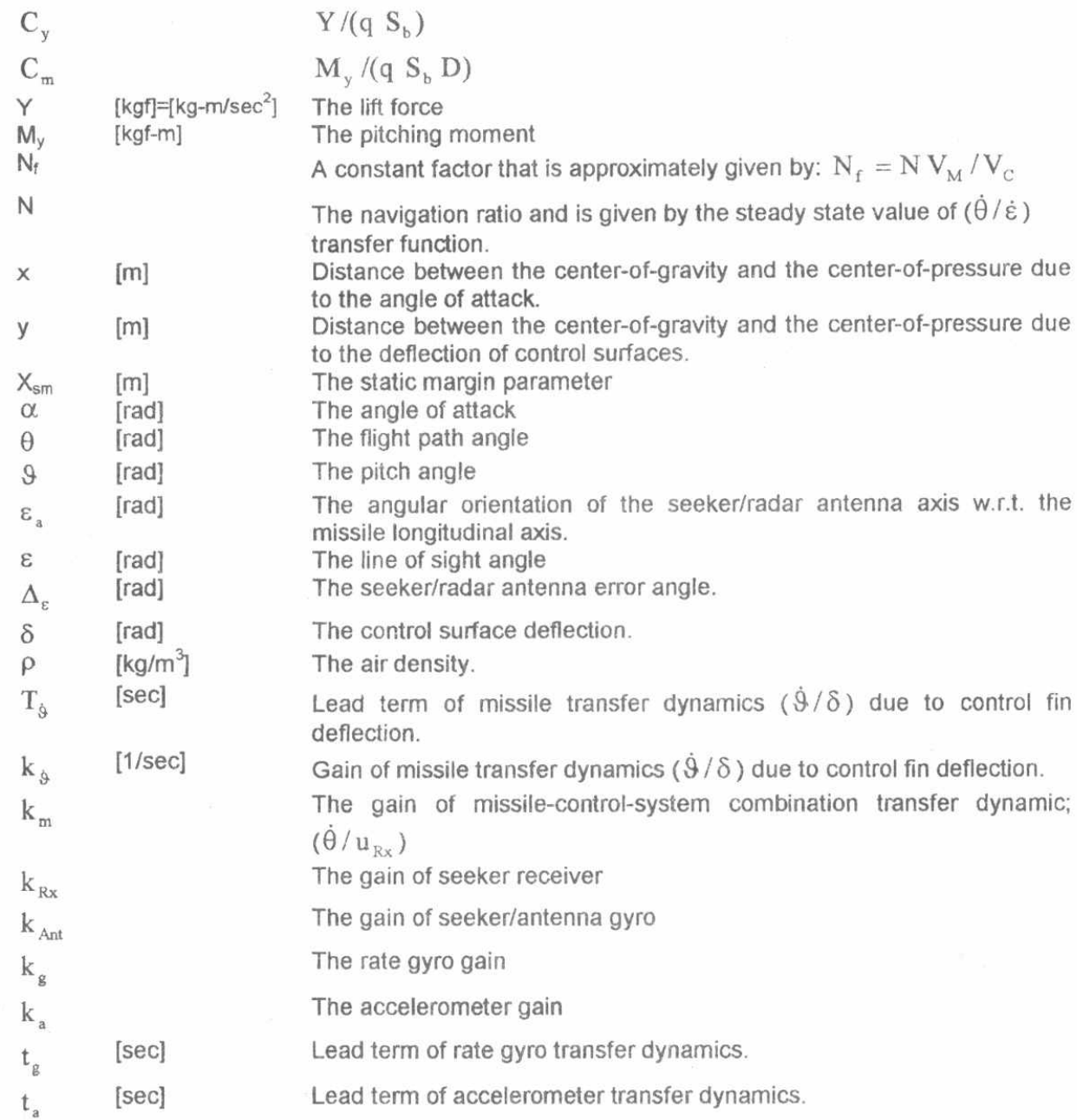

\section{Subscripts:}

$\begin{array}{llll}\text { Ant } & \text { Seeker antenna gyro/precessing mechanism } & \alpha & \partial() / \partial \alpha \\ \text { a } & \text { Accelerometer } & \dot{\alpha} & \partial() / \partial \dot{\alpha} \\ \text { g } & \text { Rate gyro } & \delta & \partial() / \partial \delta \\ \text { m } & \text { Missile-control-system combination } & \dot{\vartheta} & \partial() / \partial \dot{S}\end{array}$

\section{1- Introduction}

Homing missiles can be designed with different aerodynamic configurations among them are the variable incidence wing, the canard control, and the tail control configurations $[1,5]$. The choice between these configurations depends on some factors such as the response speed, the weight, the drag, the servo energy requirements, the convenient location of the control system components, and the size limitations. The present work is concerned with the speed of the guidance system response. The objective of the paper necessitates the availability of 
aerodynamic coefficients and derivatives for the different configurations, simultaneously. Unfortunate, the recent literature $[3,4,6,7,10,11]$ did not contain such data but it is found in eldest literature $[1,5]$.

A missile with variable incidence wing configuration can be designed to have more rapid response to the control surface deflection than either using a canard or tail control with the response to the control surface deflection than either using a cartion of the lift is immediately built up on the wing before the missile pitches to the trim angle of attack. However, considering the complete response to the seeker, control system and missile combination yields to lose some of this advantage due to the delay in surfaces deflection. This delay is attributed to different lags within the various subsystems or components of the guided missile system. In addition, the large control surface area of the variable incidence wing configuration imposes greater requirements on the servo energy and consequently a weight penalty is incurred.

In this paper, the speeds of the missile response attainable with the three aerodynamic configurations in conjunction with the proportional navigation guidance method are investigated and compared. Toward this objective, the complete guided missile system can be separated into two distinct parts: the seeker and the control system combination with aerodynamics and feedbacks, as shown in Fig. 1. The seeker is considered with high steady state gain and small lags contributed to the overall system. Thus, the dynamic characteristics of the control system combination determine to a large extent the speed of the system response.

Both the rate of pitch and the normal acceleration feedbacks are utilized in the control system and consequently the investigation starts by only the rate feedback and then the two feedbacks together. The underlying missiles are assumed to be of the boost-glide type for which the trajectory is composed of two portions; the first one is powered while the second is un-powered. Thus, the investigation will be carried out at two operating conditions concerning the Mach number; one corresponds to that at the end of boost while the second corresponds to lower speeds near the end of controlled flight. In addition, the effect of low static margin is investigated. The effects of radar noise are neglected during this investigation and the miss distance is directly proportional to the guidance system lag $[1,8]$. Therefore, the selection of the most desirable missile configuration depends upon the speed of response attainable, provided that adequate system stability is preserved.

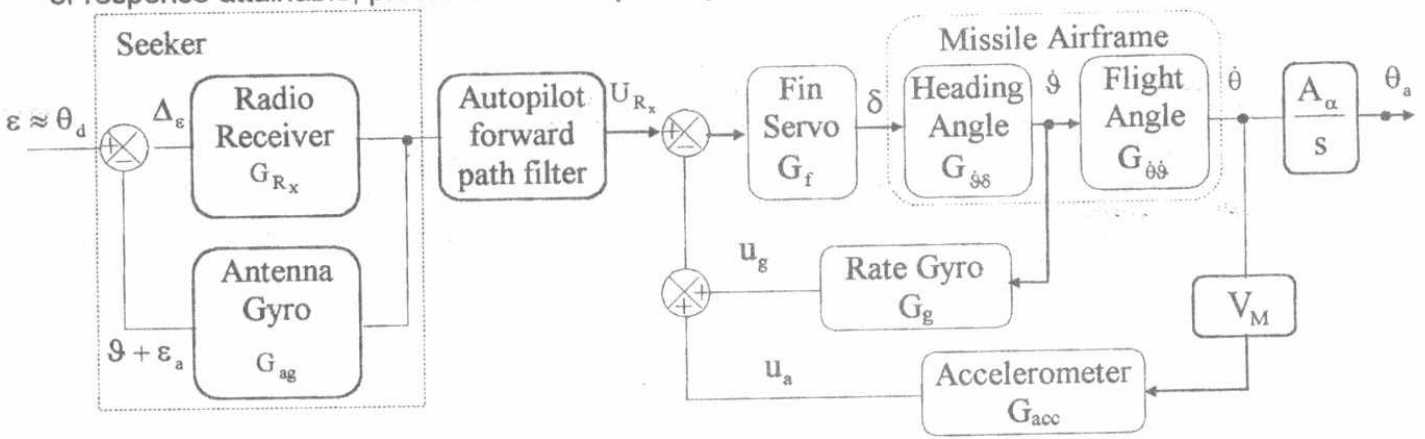

Fig. 1: Block diagram of homing guidance

\section{2- System Description}

The missile configurations considered in this work are shown in Fig.2 including the variable incidence wing, canard control and tail control configurations. These configurations have identical maneuvering capabilities and natural frequencies at an altitude of $15.24[\mathrm{~km}]$ and 
Mach number of 2.7 or 1.3 . The aerodynamic characteristics are determined in accordance with the procedure described in $[2,8,9]$ and based on the body diameter and body crossdifferent areas for the wing and tail.

The transfer functions in this paper are derived from the usual simplified equations of motion with the possibility to vary the static margin. These equations have the following form:

$$
\begin{aligned}
\mathrm{C}_{\mathrm{y} \alpha} \alpha+\mathrm{mV}_{\mathrm{m}} \dot{\alpha}-\mathrm{mV}_{\mathrm{m}} \dot{\vartheta} & =-\mathrm{C}_{\mathrm{y} \delta} \delta \\
-\mathrm{C}_{\mathrm{m} \alpha} \alpha-\mathrm{C}_{\mathrm{m} \dot{\alpha}} \dot{\alpha}-\mathrm{C}_{\mathrm{m} \dot{\vartheta}} \dot{\vartheta}+\mathrm{I}_{\mathrm{y}} \ddot{\vartheta} & =\mathrm{C}_{\mathrm{m} \delta} \delta \\
\vartheta & =\theta+\alpha
\end{aligned}
$$

To determine the effects of the static margin, it is assumed that the moment of inertia $\left(I_{y}\right)$ and the damping derivatives $\mathrm{C}_{\mathrm{m} \vartheta}$ and $\mathrm{C}_{\text {mó }}$ remain constant with the variations in the static margin. In addition, the moment derivatives $\left(\mathrm{C}_{\mathrm{m} \alpha}, \mathrm{C}_{\mathrm{m} \delta}\right)$ vary linearly with the static margin according to the following relations $[1,9]$ :

$\mathrm{C}_{\mathrm{m} \alpha}=-\frac{\mathrm{x}}{\mathrm{D}} \mathrm{C}_{\mathrm{y}_{\alpha}}, \quad \mathrm{C}_{\mathrm{m} \delta}=\frac{\mathrm{y}}{\mathrm{D}} \mathrm{C}_{\mathrm{y}_{\delta}}, \frac{\ell}{\mathrm{D}}=\frac{\mathrm{x}+\mathrm{y}}{\mathrm{D}}$
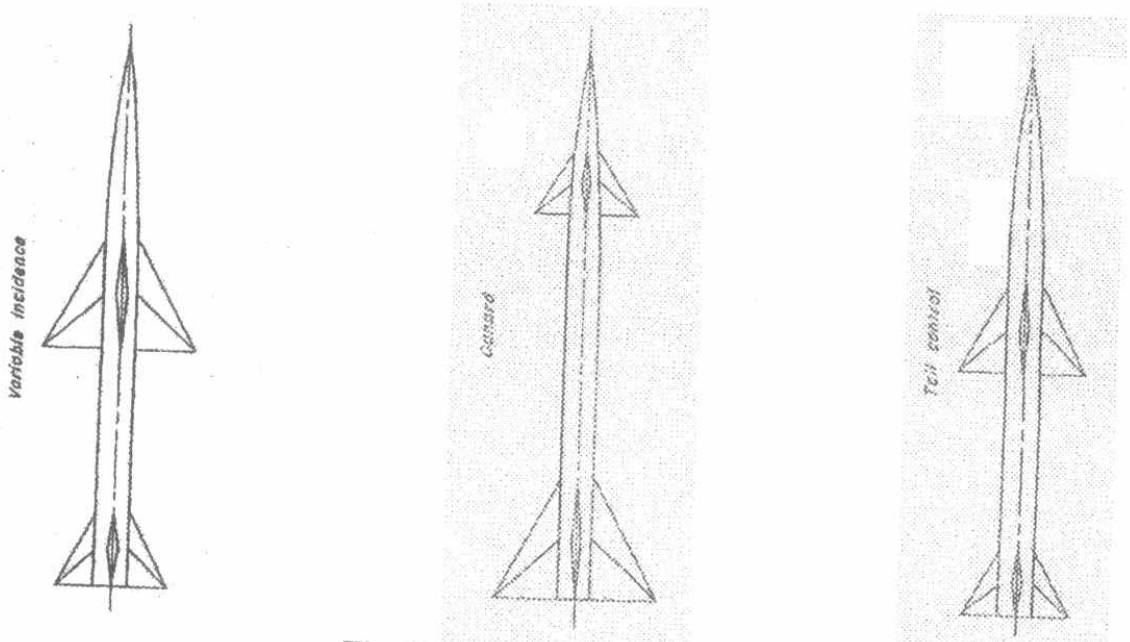

Fig. 2: Missile configurations

The transfer functions representing the missile dynamics in response to control surface doctions are obtained from equations $(1,2)$ as follows:

$$
\begin{aligned}
\mathrm{G}_{\dot{9} \delta}=\frac{\dot{\vartheta}}{\delta}=\frac{\mathrm{k}_{\dot{\vartheta}}\left[1+\left(\mathrm{T}_{\dot{\vartheta}}-\mathrm{C}_{\vartheta} \mathrm{X}_{\mathrm{sm}}\right) \mathrm{s}\right]}{\mathrm{X}_{\mathrm{sm}}+\mathrm{C}_{\vartheta_{1}} \mathrm{~s}+\mathrm{C}_{\vartheta_{2}} \mathrm{~s}^{2}} \\
\mathrm{G}_{\dot{\theta} \dot{\dot{\theta}}}=\frac{\dot{\theta}}{\dot{\vartheta}}=\frac{1+\mathrm{C}_{\theta_{1}} \mathrm{~s}+\mathrm{C}_{\theta_{2}} \mathrm{~s}^{2}}{1+\left(\mathrm{T}_{\dot{\theta}}-\mathrm{C}_{\vartheta} \mathrm{X}_{\mathrm{sm}}\right) \mathrm{s}} \\
\mathrm{G}_{\dot{\dot{\theta}}}=\frac{\dot{\theta}}{\delta}=\frac{\mathrm{k}_{\dot{\vartheta}}\left[1+\mathrm{C}_{\theta_{1}} \mathrm{~s}+\mathrm{C}_{\theta_{2}} \mathrm{~s}^{2}\right]}{\mathrm{X}_{\mathrm{sm}}+\mathrm{C}_{\vartheta_{1}} \mathrm{~s}+\mathrm{C}_{\vartheta_{2}} \mathrm{~s}^{2}}
\end{aligned}
$$

where the values of the mass and aerodynamic parameters for the underlying three configu-
rations at $M=2.7$ and $M=1.3$ and altitude the different variables are defined as follows: 


$$
\begin{aligned}
& \mathrm{X}_{\mathrm{sm}}=\frac{\mathrm{x}}{\mathrm{D}}-\frac{\mathrm{C}_{\mathrm{m} \dot{\vartheta}}}{\tau} \\
& \mathrm{k}_{\dot{\vartheta}}=\frac{\ell}{\mathrm{D}} \frac{\mathrm{C}_{\mathrm{y} \delta}}{\tau} \\
& \mathrm{T}_{\dot{\vartheta}}=\left\{\frac{\ell}{\mathrm{D}}-\frac{\mathrm{C}_{\mathrm{m} \dot{\vartheta}}}{\tau}-\frac{\mathrm{C}_{\mathrm{m} \dot{\alpha}}}{\tau}\right\} /\left\{\frac{\ell}{\mathrm{D}} \frac{\mathrm{C}_{\mathrm{y} \alpha}}{\tau}\right\} \\
& \mathrm{C}_{\vartheta}=1 /\left\{\frac{\ell}{\mathrm{D}} \frac{\mathrm{C}_{\mathrm{y} \alpha}}{\tau}\right\} \\
& \mathrm{C}_{\vartheta_{1}}=\left\{\frac{\mathrm{I}_{\mathrm{y}}}{\tau} \frac{\mathrm{C}_{\mathrm{y} \alpha}}{\tau}-\frac{\mathrm{C}_{\mathrm{m} \dot{\vartheta}}}{\tau}-\frac{\mathrm{C}_{\mathrm{m} \dot{\alpha}}}{\tau}\right\} /\left\{\frac{\mathrm{C}_{\mathrm{y} \alpha}}{\tau}\right\} \\
& \mathrm{C}_{\vartheta_{2}}=\left\{\frac{\mathrm{I}_{\mathrm{y}}}{\tau}\right\} /\left\{\frac{\mathrm{C}_{\mathrm{y} \alpha}}{\tau}\right\} \\
& \mathrm{C}_{\theta_{1}}=\left\{-\frac{\mathrm{C}_{\mathrm{m} \dot{\vartheta}}}{\tau}-\frac{\mathrm{C}_{\mathrm{m} \dot{\alpha}}}{\tau}\right\} /\left\{\frac{\ell}{\mathrm{D}} \frac{\mathrm{C}_{\mathrm{y} \alpha}}{\tau}\right\} \\
& \mathrm{C}_{\theta_{2}}=\left\{\frac{\mathrm{I}_{\mathrm{y}}}{\tau}\right\} /\left\{\frac{\ell}{\mathrm{D}} \frac{\mathrm{C}_{\mathrm{y} \alpha}}{\tau}\right\}
\end{aligned}
$$

The dynamics representing different subsystems constituting the guidance system, referring to Fig. 1, are given as follows:

\begin{tabular}{|c|c|c|c|c|c|c|c|}
\hline \multirow{2}{*}{\multicolumn{2}{|c|}{$\begin{array}{l}\text { Flight } \\
\text { dynamic } \\
\text { parameters }\end{array}$}} & \multicolumn{3}{|c|}{ Mach $=2.7$} & \multicolumn{3}{|c|}{ Mach $=1.3$} \\
\hline & & \multirow{2}{*}{$\begin{array}{c}\begin{array}{c}\text { Variable } \\
\text { incidence }\end{array} \\
798.6\end{array}$} & \multirow{2}{*}{$\begin{array}{l}\begin{array}{l}\text { Canard } \\
\text { control }\end{array} \\
798.6\end{array}$} & \multirow{2}{*}{$\begin{array}{c}\begin{array}{c}\text { Tail } \\
\text { control }\end{array} \\
798.6\end{array}$} & \multirow{2}{*}{$\begin{array}{c}\begin{array}{c}\text { Variable } \\
\text { incidence }\end{array} \\
384\end{array}$} & \multirow{2}{*}{$\begin{array}{l}\text { Canard } \\
\text { control } \\
384 \\
\end{array}$} & \multirow{2}{*}{$\begin{array}{c}\begin{array}{c}\text { Tail } \\
\text { control }\end{array} \\
384\end{array}$} \\
\hline$V_{M}$ & {$[\mathrm{~m} / \mathrm{sec}]$} & & & & & & \\
\hline$m$ & [kg] & 97.32 & 97.32 & 97.32 & 97.32 & 97.32 & 97.32 \\
\hline $\mathrm{I}_{y}$ & {$\left[\mathrm{~kg}-\mathrm{m}^{2}\right]$} & 55.574 & 55.574 & 55.574 & 55.574 & 55.574 & 55.574 \\
\hline $\mathrm{S}_{\mathrm{f}}$ & {$\left[\mathrm{m}^{2}\right]$} & 0.24248 & 0.0799 & 0.1384 & 0.24248 & 0.0799 & 0.1384 \\
\hline $\mathrm{S}_{\mathrm{r}}$ & {$\left[\mathrm{m}^{2}\right]$} & 0.1059 & 0.2759 & 0.0836 & 0.1059 & 0.2759 & 0.0836 \\
\hline$S_{b}$ & {$\left[\mathrm{~m}^{2}\right]$} & 0.0324 & 0.0324 & 0.0324 & 0.0324 & 0.0324 & 0.0324 \\
\hline$I_{f}$ & [m] & 0.061 & 1.1247 & 0.0183 & 0.061 & 1.1247 & 0.0183 \\
\hline$I_{1}$ & [m] & 1.3899 & 0.9815 & 1.4326 & 1.3899 & 0.9815 & 1.4326 \\
\hline D & [m] & 0.2033 & 0.2033 & 0.2033 & 0.2033 & 0.2033 & 0.2033 \\
\hline$\tau$ & [sec] & 40.4 & 40.4 & 40.4 & 84.1 & 84.1 & 84.1 \\
\hline$\dot{i}_{y}$ & {$\left[\sec ^{2}\right]$} & 0.142 & 0.142 & 0.142 & 0.615 & 0.615 & 0.615 \\
\hline \multicolumn{2}{|l|}{$X / D$} & 0.99 & 0.99 & 1.37 & 0.906 & 1.2 & 1.41 \\
\hline \multicolumn{2}{|l|}{ I/D } & 1.96 & 9.89 & -5.68 & 2.6 & 15.9 & -5.64 \\
\hline \multicolumn{2}{|c|}{$\mathrm{C}_{\mathrm{y \alpha}}$} & 23.8 & 23.8 & 17.2 & 38.3 & 38.1 & 26.3 \\
\hline
\end{tabular}

$$
\begin{aligned}
\mathrm{G}_{\mathrm{f}}=\frac{\mathrm{k}_{\mathrm{f}}}{1+0.05 \mathrm{~s}} & \mathrm{G}_{\mathrm{acc}}=\frac{\mathrm{k}_{\mathrm{a}}\left(1+\mathrm{t}_{\mathrm{a}} \mathrm{s}\right)}{1+0.01 \mathrm{~s}} \\
\mathrm{G}_{\mathrm{g}}=\frac{\mathrm{k}_{\mathrm{g}}\left(1+\mathrm{t}_{\mathrm{g}} \mathrm{s}\right)}{1+0.01 \mathrm{~s}} & \mathrm{G}_{\mathrm{ag}}=\frac{\mathrm{k}_{\text {Ant }}}{\mathrm{s}(1+0.02 \mathrm{~s})}
\end{aligned} \quad \mathrm{G}_{\mathrm{Rx}}=\mathrm{k}_{\mathrm{Rx}}
$$

In addition, the output from the seeker, which is the reference command to the control system (Fig. 1), is given as follows:

$\mathrm{U}_{\mathrm{Rx}}=\frac{\mathrm{k}_{\mathrm{Rx}}\left(0.02 \mathrm{~s}^{2}+\mathrm{s}\right)}{0.02 \mathrm{~s}^{2}+\mathrm{s}+\mathrm{k}_{\mathrm{Rx}} \mathrm{k}_{\text {Ant }}} \varepsilon=\frac{\mathrm{k}_{\mathrm{Rx}}(0.02 \mathrm{~s}+1)}{0.02 \mathrm{~s}^{2}+\mathrm{s}+\mathrm{k}_{\mathrm{Rx}} \mathrm{k}_{\text {Ant }}} \dot{\varepsilon}$

Table-1: Missile mass and aerodynamic parameters for $15.24[\mathrm{~km}]$ altitude 


\begin{tabular}{|ll|l|l|l|l|l|l|}
\hline $\mathrm{C}_{\mathrm{y} \delta}$ & {$[1 / \mathrm{rad}]$} & 9.87 & 2.93 & 5.69 & 18 & 4.08 & 16.6 \\
\hline $\mathrm{C}_{\mathrm{m} \dot{ }}$ & {$[1 / \mathrm{rad} / \mathrm{sec}]$} & -0.0916 & -0.151 & -0.078 & -0.414 & -0.62 & -0.348 \\
\hline $\mathrm{C}_{\mathrm{m} \dot{\alpha}}[1 / \mathrm{rad} / \mathrm{sec}]$ & -0.0218 & -0.026 & -0.0173 & -0.204 & -0.159 & -0.156 \\
\hline
\end{tabular}

\section{3- Control System}

The block diagram representing the missile control system is shown in the right part of Fig. 1; where it produces a missile rate of turn $(\dot{\theta})$ proportional to the seeker output voltage $U_{R x}$, in the steady state. The constant of proportionality (proportional navigation constant or guidance gain) depends on the individual gains of different sub systems as follows:

$\mathrm{k}_{\mathrm{m}}=\left.\frac{\dot{\theta}}{\mathrm{u}_{\mathrm{R}_{\mathrm{x}}}}\right|_{\mathrm{sS}}=\frac{\mathrm{k}_{\mathrm{f}} \mathrm{k}_{\dot{g}}}{\mathrm{X}_{\mathrm{sm}}+\mathrm{k}_{\mathrm{f}} \mathrm{k}_{\mathrm{g}} \mathrm{k}_{\dot{g}}+\mathrm{V}_{\mathrm{M}} \mathrm{k}_{\mathrm{f}} \mathrm{k}_{\mathrm{a}} \mathrm{k}_{\dot{g}}}$

The rate feedback is necessary to provide increased damping since the missiles themselves are poorly damped, having damping ratios from 0.04 to 0.07 (depending on the configuration) for the normal design of the static margin and for a Mach number of 2.7. In order to obtain adequate damping, it is necessary to include a rate gyro lead $\left(\mathrm{t}_{\mathrm{g}}\right)$ approximately equals to the control servo lag. With only rate feedback (i.e., with $k_{a}=0$ ), the control-system gain can be selected so that the system oscillation frequency is approximately the same as the missile natural frequency $[1,5]$. Since at low static margins the missile natural frequency is low, this control system was only investigated at the normal design static margin where a rapid response could be expected.

With normal acceleration feedback included, it is shown in reference [9] that a system oscillation frequency can be obtained that is higher than the missile natural frequency. Therefore, the investigation included a range of missile static margins for this control system and results are presented for the normal design static margin and for a very small negative static margin. The variation of the proportional navigation constant or guidance gain against the Mach number and different subsystems' gains is derived as:

$$
\mathrm{N}=\frac{\mathrm{k}_{\mathrm{m}}}{\mathrm{k}_{\text {Ant }}}=\frac{\mathrm{k}_{\mathrm{f}}}{\mathrm{k}_{\text {Ant }}} \frac{\mathrm{k}_{\dot{g}}}{\mathrm{X}_{\text {sm }}+\mathrm{k}_{\mathrm{f}} \mathrm{k}_{\mathrm{g}} \mathrm{k}_{\dot{\mathrm{g}}}+\mathrm{V}_{\mathrm{M}} \mathrm{k}_{\mathrm{f}} \mathrm{k}_{\mathrm{a}} \mathrm{k}_{\dot{\mathrm{g}}}}
$$

Thus, the servo gain related to the Mach number and the guidance gain is obtained as follows:

$\frac{k_{f}}{k_{\text {Ant }}}=\frac{N\left(X_{s m}+k_{f} k_{g} k_{\dot{g}}+V_{M} k_{f} k_{a} k_{\dot{g}}\right)}{k_{\dot{g}}}$

\section{4- Guidance System}

The block diagram representing the guidance system is shown in Fig. 1. In reference [1], it was shown that a rapid response could be obtained with this system in which the seeker antenna is stabilized in space so that no coupling occurs between the antenna motion and the missile turning motion. With a high value for the seeker open loop gain $\left(\mathrm{k}_{\mathrm{Rx}} \mathrm{k}_{\mathrm{Ant}}\right)$, the seeker responds with a voltage output proportional to the rate of the line of sight rotation $(\dot{\varepsilon})$ with negligible lag $\left(\mathrm{Eq}^{\mathrm{n}}(6)\right.$ yields $\left.\left\{\mathrm{u}_{\mathrm{Rx}} / \dot{\varepsilon}\right\}_{\mathrm{ss}}=1 / \mathrm{k}_{\text {Ant }}\right)$. The control system produces a missile rate of turn $(\dot{\theta})$ proportional to the seeker steady state output so that the complete guidance system produces a proportional navigation in the steady state in compliance with the following equation: 
$\frac{\dot{\theta}}{\dot{\varepsilon}}=\mathrm{N}=\frac{\mathrm{k}_{\mathrm{m}}}{\mathrm{k}_{\text {Ant }}}$

Since there is negligible lag in the seeker and no coupling between the seeker and the missile motions, the speed of response of the complete system depends predominantly on the dynamic characteristics of the missile control system combination.

\section{5- Performance Analysis}

The equations describing the dynamic characteristics of the missiles, control system, and seeker are solved for a step $\dot{\varepsilon}_{\mathrm{a}}$ input by means of Simulink with MATLAB $®$. The $\dot{\theta}$ output responses are optimized for the design flight condition $(M=2.7)$ by varying system gains and adequate stability for to determine the most rapid response obtainable consistent with constants, as dimized gains and lead determine the deffect an $M=2.7$, are used with the changed aerodynamic parameters to come flight speed on the system responses. Then, a comparison of the $(\dot{\theta} / \dot{\varepsilon})$ steady state response for different values is to be carried out. To determine the effect of static margin, the parameter $\mathrm{X}_{\mathrm{sm}}$ is varied because of the convenient manner in which it occurs in the missile transfer function, equations (3). Results are presented with both the normal design value of $X_{s m}$ and with $X_{s m}=0$ for the control system having both rate and normal acceleration feedback. With a rate feedback only, the results include just the normal design value of $X_{\mathrm{sm}}$

The results are for a navigation ratio of 3 , which was chosen on the basis of desirable trajectory characteristics and anticipated noise effects. However, since for this guidance system the navigation ratio can be adjusted independently of the dynamics [1], the results apply for all navigation ratios that might be physically realizable. Design trials had been carried out from which the design variables corresponding to the best system performance in addition to the figure number are summarized in
Table-2.

Table-2: Optimized gains and lead constants

\begin{tabular}{|c|c|c|l|l|c|c|}
\hline Fig. & $N=\mathrm{k}_{\mathrm{m}} / \mathrm{k}_{\text {Ant }}$ & $\mathrm{k}_{\mathrm{f}} \mathrm{k}_{\mathrm{a}} \mathrm{k}_{\dot{\jmath}} \mathrm{V}_{\mathrm{M}}$ & \multicolumn{1}{|c|}{$\mathrm{t}_{\mathrm{a}}$} & $\mathrm{k}_{\mathrm{f}} \mathrm{k}_{\mathrm{g}} \mathrm{k}_{\dot{\jmath}}$ & $\mathrm{t}_{\mathrm{g}}$ & $\mathrm{k}_{\mathrm{Rx}} \mathrm{k}_{\text {Ant }}$ \\
\hline 3 & 3 & 0 & 0 & 0.02 & 0.05 & 30 \\
\hline 4 & 3 & 10 & 0.013 & 0.5 & 0.05 & 15 \\
\hline 5 & 3 & 10 & 0.008 & 0.24 & 0.06 & 15 \\
\hline
\end{tabular}

\subsection{Rate Feedback Only}

The optimized responses of the three missiles at $M=2.7$ with the normal design static margin the optimum gains are listed feedback only are shown in Fig. 3-a. Corresponding values of slightly more rapid response than the other The variable incidence configuration has only a to the effect of the system lags on the initio configurations. It can be seen that this is due that the variable incidence missile would speed. The oscillation frequency of all arger advantage in terms of the response value $(\cong 2 \mathrm{~Hz})$.

The responses for the same gains of Fig. 3-a but with the aerodynamic parameters calculated at $M=1.3$ are shown in Fig. 3-b. The navigation ratio $(N)$ has increased by about about 10 percent for the incidence and tail control configurations while it is decreased by value of $\left(\mathrm{k}_{\mathrm{f}} \mathrm{k}_{\mathrm{g}} \mathrm{k}_{\mathrm{s}}\right)$ and the variation of of the smartion. This shown in equation (8). Sain $\left(\mathrm{k}_{\mathrm{g}} / \mathrm{X}_{\mathrm{sm}}\right)$ with Mach number as shown in equation (8). Since $\mathrm{k}_{\mathrm{f}} \mathrm{k}_{\mathrm{g}} \mathrm{k}_{\vartheta} \ll \mathrm{X}_{\mathrm{sm}}$, the value of $\left(\mathrm{k}_{\mathrm{g}} / \mathrm{X}_{\mathrm{sm}}\right)$ increases with 
decreasing Mach number for the variable-incidence and tail-control configurations while it decreases with decreasing Mach number for the canard configuration.

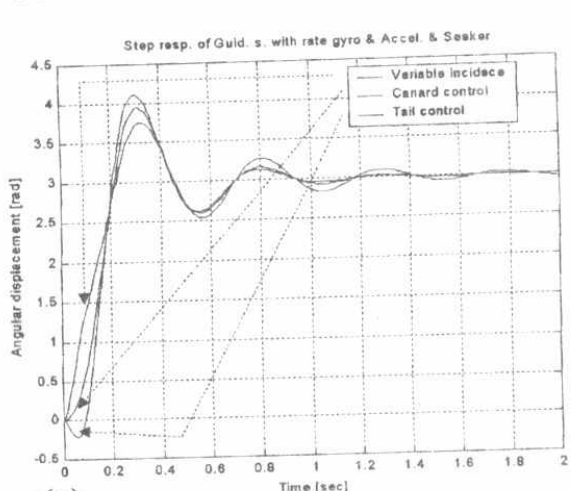

(a)

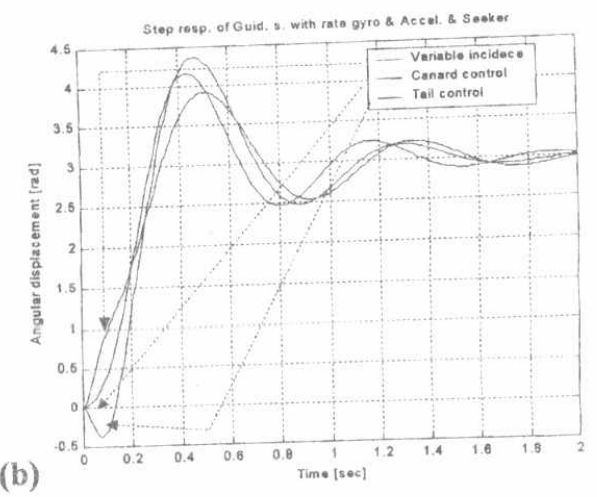

(b)

Fig. 3: System response with rate feedback only (a) $M=2.7$ and (b) $M=1.3$

Simplified trajectory studies show that in order to maintain desirable trajectory characteristics, a factor $\left(\mathrm{N}_{\mathrm{f}}\right)$ that depends on the navigation ratio, on the missile flight speed $V_{M}$ and on the missile target closing speed $V_{C}$, must be kept constant [2]. The too large value for this factor yields unstable trajectory while the too small value results in a sluggish trajectory in addition to large miss distance. This factor is defined by the following relationship:

$$
N_{f}=\frac{N V_{M} \cos (\varepsilon-\theta)}{V_{M} \cos (\varepsilon-\theta)-V_{T} \cos (\varepsilon)} \cong \frac{N V_{M}}{V_{C}}
$$

It is clear that $\mathrm{N}_{\mathrm{f}}$ can be maintained constant with decreasing the missile flight speed if the navigation ratio $\mathrm{N}$ is chosen/designed to

1- increase for a head on attack,

2- remain constant for a beam attack, and

3- decrease for a tail attack.

It is apparent that without automatic gain adjustment, none of the underlying missiles is capable for maintaining optimum trajectory characteristics with variations in the flight speed for all initial conditions. However, the magnitude of the change in $\mathrm{N}$ for the three missile configurations appears to be small enough so that the above effect should not be serious for the speed variation considered herein.

\subsection{Rate and Normal Acceleration Feedbacks}

The optimized responses of the three missiles at $M=2.7$ with the normal design static margin for the control system with both rate and acceleration feedbacks are shown in Fig. 4-a. Corresponding values of the optimum gains and lead constants are listed in Table- 2 . It is seen that, with normal acceleration feedback in the control system, the frequency of the overall response, though different for the various missiles, is higher for all three missiles than the missile design frequency. This, of course, is the primary advantage of the acceleration control system. It is possible to attain an oscillation frequency, and therefore speed of response, higher than that of the airframe alone.

in terms of response speed, the order of merit of the missiles is the reverse of that which occurred with rate feedback only, the tail control having the most rapid speed of response and highest oscillation frequency, but also having the largest initial overshoot. This is due to the relative magnitude of the numerator terms in the missile $\{\dot{\theta} / \dot{\vartheta}\}$ transfer function, $C_{\theta_{1}}$ and $\mathrm{C}_{\theta_{2}}$. The small negative terms for the tail-control configuration result in a higher frequency 
than the small positive terms for the canard and result in a higher frequency than the larger positive terms for the variable-incidence configuration.
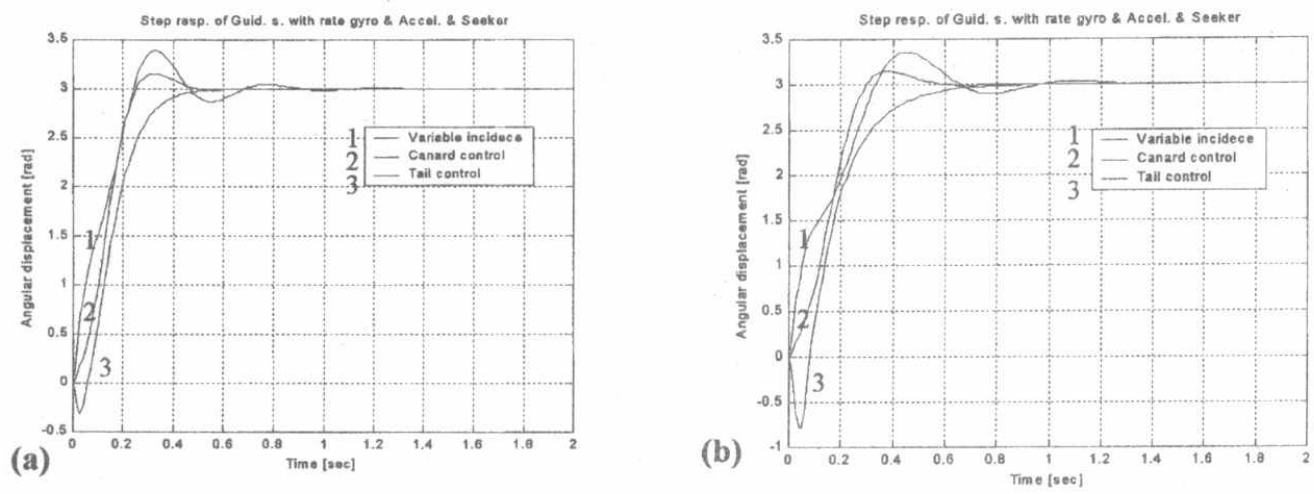

Fig. 4: System response with both rate and acceleration feedbacks (a) $M=2.7$ and (b) $M=1.3$

The responses for the same gains and lead constants utilized in Fig. 4-a but with the $M=1.3$ aerodynamic parameters and missile flight speed, are shown in Fig. 4-b. For all three missiles the navigation ratio has approximately doubled. This is due to the fact that the navigation ratio is approximately inversely proportional to the missile flight speed as shown in following equations:

$\mathrm{N}=\frac{\mathrm{k}_{\mathrm{m}}}{\mathrm{k}_{\text {Ant }}} \cong \frac{1}{\mathrm{~V}_{\mathrm{M}} \mathrm{k}_{\text {Ant }} \mathrm{k}_{\mathrm{a}}}$

Since $\left[\mathrm{X}_{\mathrm{sm}}+\mathrm{k}_{\mathrm{f}} \mathrm{k}_{\mathrm{g}} \mathrm{k}_{\vartheta}\right] \ll\left[\mathrm{V}_{\mathrm{M}} \mathrm{k}_{\mathrm{f}} \mathrm{k}_{\mathrm{a}} \mathrm{k}_{\vartheta}\right]$. With large increase in the navigation ratio such as occur with this control system, trajectory instability is likely to occur for tail chases as the missile flight speed decreases unless some sort of automatic gain control is provided.

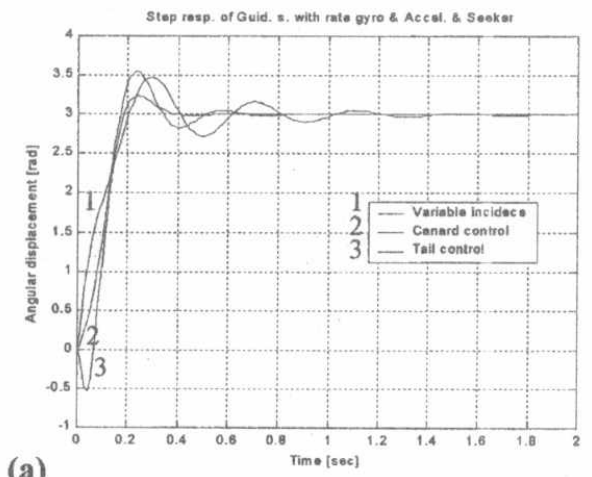

(a)

Fig. 5: System response with both rate and acceleration feedbacks and low static margin (a) $\mathrm{M}=2.7$ and (b) $\mathrm{M}=1.3$

With low static margin (for $X_{s m}=0$ ), the optimized responses at $M=2.7$ and the responses at $\mathrm{M}=1.3$ are shown in Figs 5 -a and $5-b$, respectively. At this static margin the missiles themselves are slightly unstable statically, but the optimized responses are almost identical to those for the normal design static margin. These results show the ability of an acceleration 
control system to provide a rapid response for a wide range of aerodynamic parameters. Since the responses are so nearly identical to those for the normal static margin, the previous discussion is equally applicable to the low-static-margin case.

\section{6- Conclusions}

The paper is devoted to investigate the maximum speeds of missile response that could be attained by three aerodynamic configurations in combination with a particular proportional navigation guidance system. These configurations include a variable-incidence-wing, a canard, and a tail-control. The missile control system utilized both pitch-rate and normal acceleration feedbacks. From the obtained results, the following conclusions can be drawn:

- The optimum configuration in terms of the missile response speed depends on the characteristics of the control system.

- With pitch-rate feedback only, the oscillation frequency of the overall response is very nearly that of the missile alone, and the variable-incidence configuration allows a slightly more rapid system response than either the canard or tail-control configuration.

- With both pitch-rate and normal acceleration feedbacks, the oscillation frequency is higher than that of the missile alone, and the tail-control configuration allows the highest system oscillation frequency and the most rapid speed of response. However, this configuration has the largest initial overshoot.

- If normal acceleration feedback is used with a boost-glide missile, objectionable navigation ratio variations with missile-flight-speed changes may exist, necessitating automatic gain adjustment in flight.

\section{References}

[1] Abramovitz, M., Theoretical Investigation of the Performance of Proportional Navigation Guidance Systems: Effect of Method of Positioning the Radar Antenna on the Speed of Response, NACA RM A52E27, 1952.

[2] Anon, AN/DPN-7 Guidance System and Associated Equipment, Integrated Final Technical Report, Fairchild Rep. No. 6E-695, Feb. 19, 1951.

[3] Barrowman, J., Calculating the Center of Pressure of a Model Rocket, Centuri, Phoenix, Arizona, TIR-33, 1988.

[4] Blake, W.B., Missile DATACOM: User's manual, Air Force Research Laboratory, USA, 1998.

[5] Blakelock, J.H., Automatic Control of Aircraft and Missiles, John Wiley \& Sons, Second Edition, 1991.

[6] Hemsch, M.J., Tactical Missile Aerodynamics: General Topics, AIAA, Vol. 141, 1992.

[7] Hemsch, M.J. and J.N. Nielsen, Tactical Missile Aerodynamics, AIAA, Vol. 104, 1986.

[8] Johnson, R. L., Sparrow: Investigation of the Missile Minimum Natural Frequency Requirement, Douglas MTM 203, May 22, 1950

[9] Matthews, H. F., and E.C. Stewart, A Comparison of the Calculated MaximumManeuver Response Characteristics of Three Air-to-Air. Beam-Rider, Guided Missiles Having Different Lift Ratios, NACA RM A51F18, 1951.

[10] Mendenhall, M.R., Tactical Missile Aerodynamics: Prediction Methodology, AIAA, Vol. 142, 1992.

[11] Sun, J and R.M. Cummings, Evaluation of Missile Aerodynamic Characteristics Using Rapid Prediction Techniques, Journal Spacecraft, Vol. 21, No. 6, pp513-520, Nov.Dec., 1984. 